\title{
Design and Analysis of 25 \& 35 Gbps Optical Communication System based on APDCDM Technique
}

\author{
Puja Kant \\ Electronics \& Communication Department, \\ BIST, Bhopal MP, INDIA
}

\author{
Manish Saxena \\ Electronics \& Communication Department, \\ BIST, Bhopal MP, INDIA
}

\begin{abstract}
A 25 and 35 Gbps Absolute Pole Duty cycle division multiplexing (APDCDM) based communication system is designed successfully. A technique for estimation of BER is developed for four users APDCDM based optical communication system, referring to the data recovery rules. The performance parameters like SNR, Q-factor and BER are calculated for the transmission rate $25 \mathrm{Gbps}$ and $35 \mathrm{Gbps}$ in this system. After design and simulation it is concluded that the performance of system is reduces for higher data transmission rate as compare to lower data transmission rate.
\end{abstract}

\section{Keywords}

Bit error Rate (BER), Signal to Noise Ratio (SNR), Q-factor

\section{INTRODUCTION}

The transmission of signals over a distance for the purpose of communication began thousands of years ago with the use of smoke signals and drums in Africa, America and parts of Asia. Communication can be defined as the exchange of information between sender and receiver through an accepted code of symbols. In 1830s, electrical telecommunication systems started to appear where information is in form of electrical signal. The Morse telegraph was introduced in the 1860s and transmission rate was $1 \mathrm{bit} / \mathrm{s}$. Multiplexing began with telegraph systems; this allowed two individual messages to travel the same direction on the line at the same time, which was called duplexing. The invention of the telephone in 1876s and first coaxial cable system in 1940 s, with the capability to transmit 300 voice channels. The first microwave system was put into service in 1948 s, with a carrier frequency of $4 \mathrm{GHz}$. Coaxial and microwave systems were operating at $100 \mathrm{Mbit} / \mathrm{s}$. High speed coaxial systems need repeater spacing of $1 \mathrm{~km}$. Increase of the bandwidth and decreases of the cost per transmitted bit for optical communication systems started during the 1990s.

The transmission of signals over a distance for the purpose of communication began thousands of years ago with the use of smoke signals and drums in Africa, America and parts of Asia. Communication can be defined as the exchange of information between sender and receiver through an accepted code of symbols.

In 1830s, electrical telecommunication systems started to appear where information is in form of electrical signal. The Morse telegraph was introduced in the 1860s and transmission rate was 1bit/s. Multiplexing began with telegraph systems; this allowed two individual messages to travel the same direction on the line at the same time, which was called duplexing. The invention of the telephone in 1876 s and first coaxial cable system in 1940 s, with the capability to transmit 300 voice channels. The first microwave system was put into service in 1948 s, with a carrier frequency of $4 \mathrm{GHz}$. Coaxial and microwave systems were operating at 100Mbit/s. High speed coaxial systems need repeater spacing of $1 \mathrm{~km}$. Increase of the bandwidth and decreases of the cost per transmitted bit for optical communication systems started during the 1990s.

The never-ending bandwidth requirement results in advancement of communication technology for bulk data transfer through the networks. The exponential increase in network capacity has made the use of various multiplexing techniques mandatory for every communication system [1]. For efficient use of available bandwidth an alternative multiplexing scheme called as duty cycle division multiplexing (DCDM) and subsequently AP-DCDM (absolute polar duty cycle division multiplexing) were reported. In these techniques, users can transmit data with different duty cycle simultaneously over the communication media. The information can be easily distinguished from the received signal at the receiver side, based on the signal amplitude and the duty cycle [2-5]

In this paper, we investigated a $25 \& 35$ Gbps APDCDM Optical communication system. A technique for estimation of BER is developed for four users APDCDM based optical communication system, referring to the data recovery rules. The performance parameters like SNR, Q-factor and BER are calculated for the transmission rate $25 \mathrm{Gbps}$ and $35 \mathrm{Gbps}$ in this system.

\section{THEORITICAL ANALYSIS}

Based on the number of users, there are $2^{\text {n }}$ possible combinations of bits for ' $n$ ' users. In the multiplexed signal, each of these combinations produces a unique symbol. For the four users the total number of combination will be $2^{4}=16$. Figure 1,

\begin{tabular}{|c|c|c|c|}
\hline $\begin{array}{c}\text { S. } \\
\text { No } \\
.\end{array}$ & Rules & Case & Data \\
\hline 1 & SP-4<TH-1 & 1 & 0 \\
\hline 2 & SP-4<TH-1 & 2 & 0 \\
\hline 3 & SP-4<TH-1 & 3 & 0 \\
\hline 4 & SP-4<TH-1 & 4 & 0 \\
\hline 5 & SP-4<TH-1 & 5 & 0 \\
\hline 6 & SP-4<TH-1 & 6 & 0 \\
\hline 7 & TH-1<=SP-4<TH-2 & 7 & 1 \\
\hline 8 & SP-4<TH-1 & 8 & 0 \\
\hline 9 & TH-1<=SP-4<TH-2 & 9 & 1 \\
\hline 10 & TH-1<=SP-4<TH-2 & 10 & 1 \\
\hline 11 & TH-1<=SP-4<TH-2 & 11 & 1 \\
\hline 12 & TH-1<=SP-4<TH-2 & 12 & 1 \\
\hline 13 & TH-1<=SP-4<TH-2 & 13 & 1 \\
\hline 14 & TH-1<=SP-4<TH-2 & 14 & 1 \\
\hline 15 & TH-1<=SP-4<TH-2 & 15 & 1 \\
\hline 16 & TH-1<=SP-4<TH-2 & 16 & 1 \\
\hline
\end{tabular}

Figure 1: All possible combination of four users

Shows the possible combinations and Figure 2 Shows absolute multiplexed signal for case 1 to 16.Similarly we design absolute multiplexing signal for all other cases. 

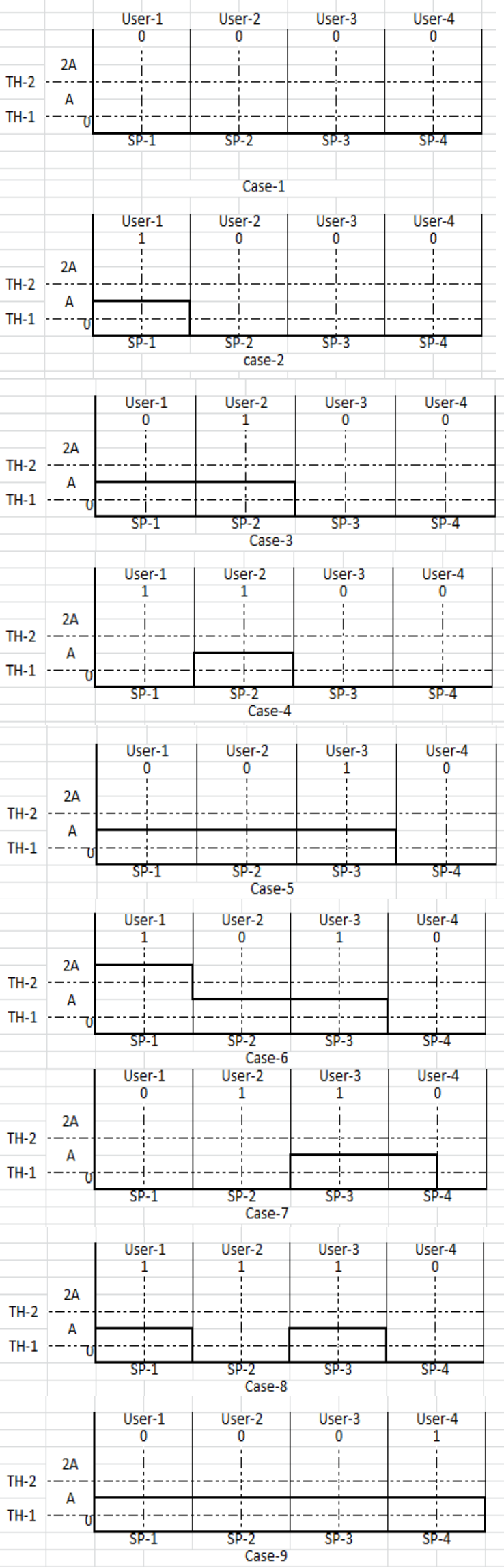
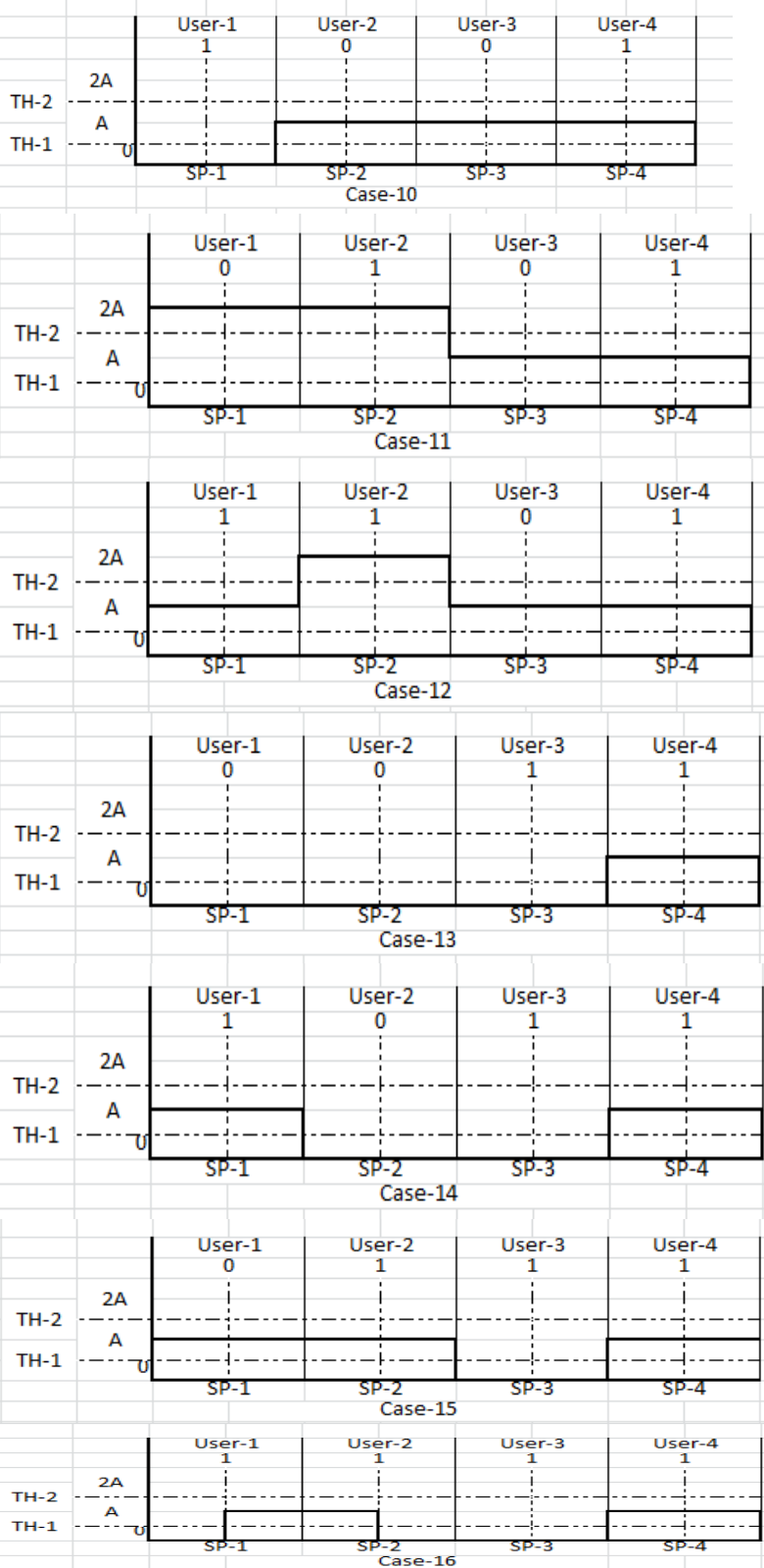

Figure 2: Absolute multiplex signal (case no.1 to 16)

\section{RESULT AND DISCUSSIONS}

\section{A. BER vs Length}

Figure 3 and figure 4 shows the graph of received BER versus length for the 25 \& 35 Gbps APDCDM systems with four different filters. Received optical power is the input optical power required at the receiver before photo detector.

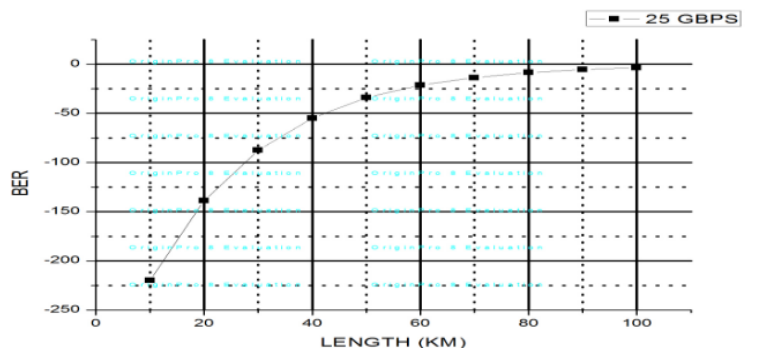

Figure 3: BER v/s Link length 


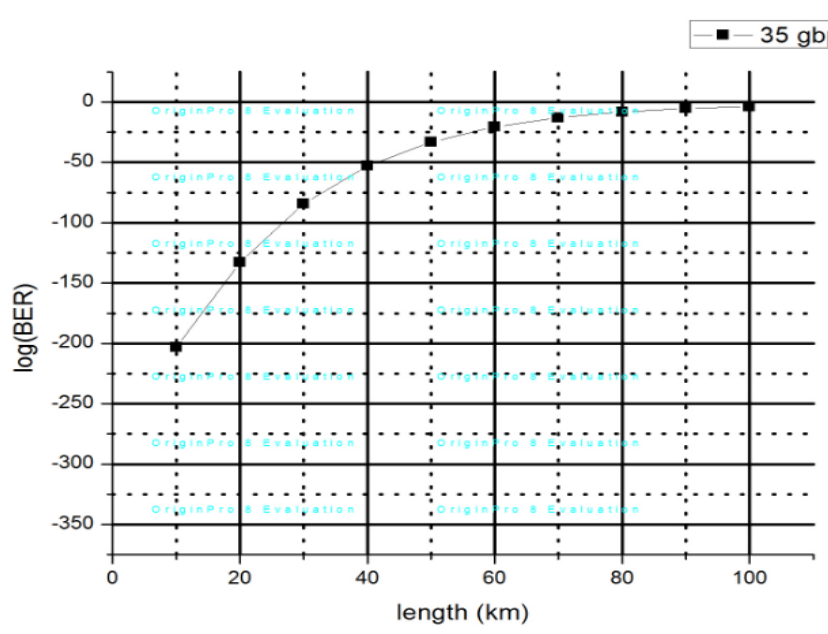

Figure 4: BER v/s Link length

\section{$B$. Q-Factor versus Length}

The figure 5 shows the graph of received Q-factor versus length for the $25 \& 35 \mathrm{Gbps}$ APDCDM systems with different filters, this work is similar to SNR calculation and setup parameters also same.

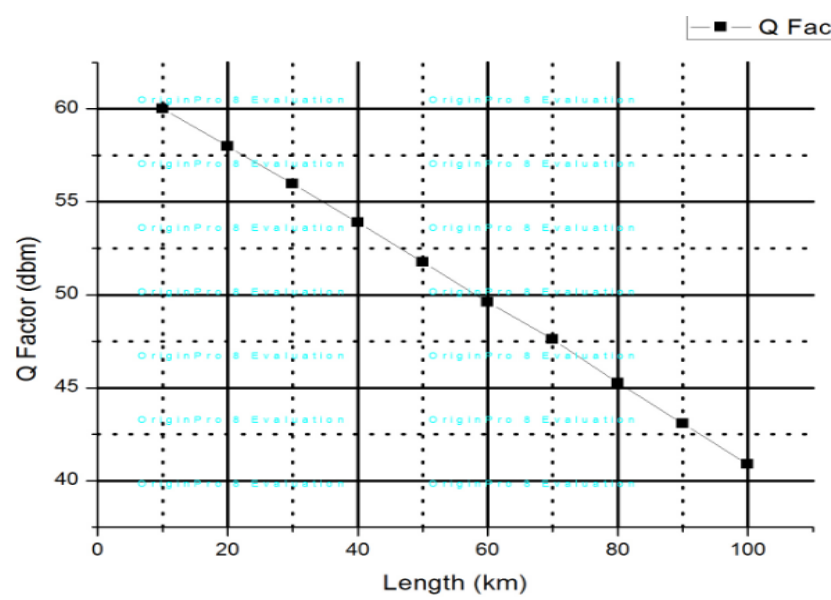

Figure 5: Q-factor v/s Link length

\section{SNR versus Length}

The graph of received electrical SNR versus length for the 25 \& $35 \mathrm{Gbps}$ APDCDM system with four users is shown in figure 6 and figure 7 respectively. Here signal is tested for the fibre length of $100 \mathrm{~km}$ and SNR is calculated for every $20 \mathrm{~km}$ distance. It is observed that as length increases the SNR decreases for all the users.

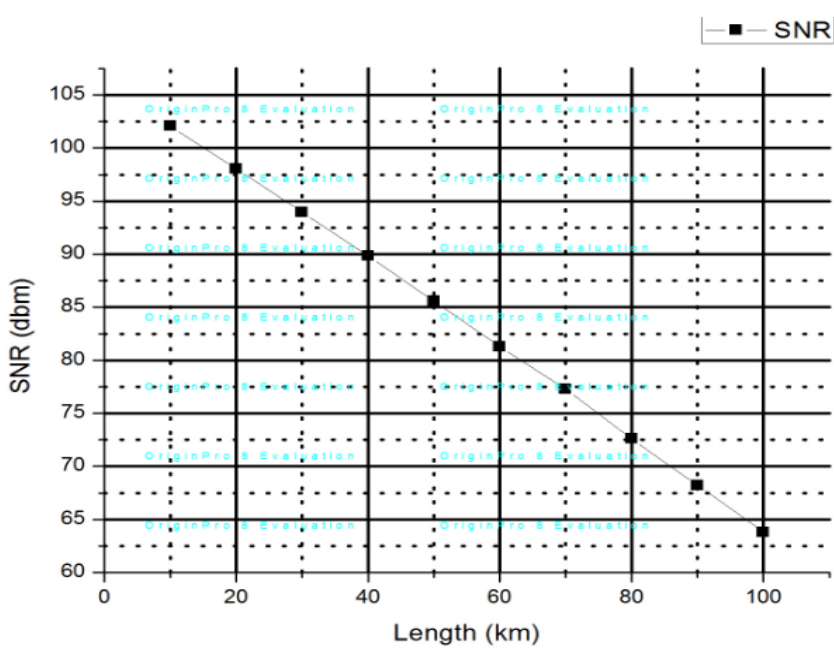

Figure 6: SNR v/s Link length

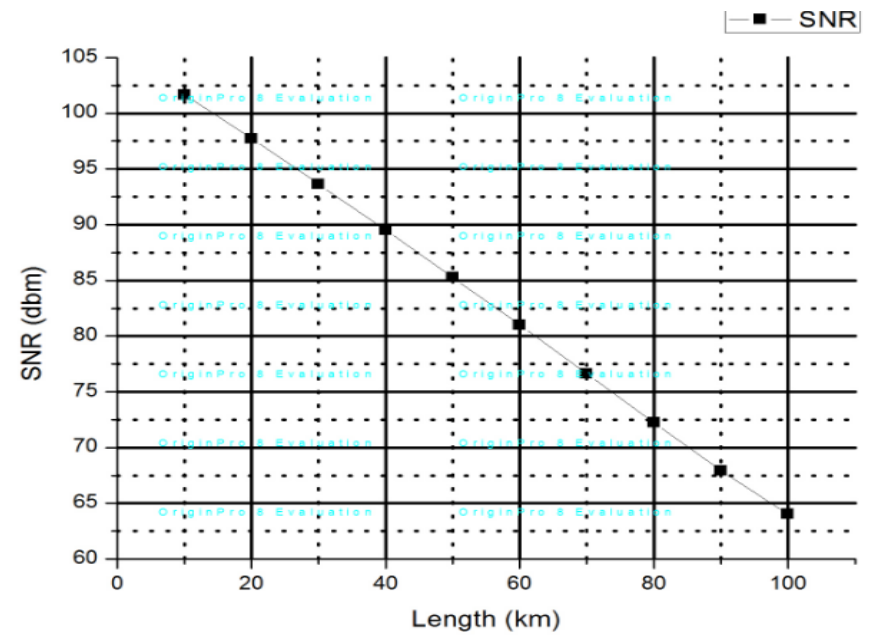

Figure 7: SNR v/s Link length

\section{CONCLUSION}

A $25 \mathrm{Gbps}$ and $35 \mathrm{Gbps}$ absolute polar duty cycle division multiplexing (APDCDM) based communication system is designed successfully. A technique for estimation of BER is developed for four users APDCDM based optical communication system, referring to the data recovery rules. The performance parameters like SNR, Q-factor and BER are calculated for the transmission rate $25 G b p s$ and $35 G b p s$ in this system. After design and simulation it is concluded that the performance of system is reduces for higher data transmission rate as compare to lower data transmission rate.

\section{ACKNOWLEDGMENT}

I express my profound sense of gratitude to Prof. manish Saxena, Department of Electronics and communication and Prof. Vineet Tiwari Department of Electronics and communication, BIST Bhopal for their useful suggestion and support. 


\section{REFERENCES}

[1] M. K. Abdullah, G. A. Mahdiraji, A. M. Mohammadi, M. Mokhtar and A. F. Abas "Duty Cycle Division Multiplexing (DCDM), A New Electrical Multiplexing Technique for High Speed Optical Communication Systems", Proceedings of IEEE 2008 6th National Conference on Telecommunication Technologies and IEEE 2008 2nd Malaysia Conference on Photonics, 26-27 August 2008, Putrajaya, Malaysia.

[2] Jyotsna Rani Mahapatra, Manisha Chattopadhyay "Spectral characteristic of UNIFORM FIBER BRAGG GRATING using couple mode theory" International Journal of Electrical, Electronics and Data Communication, ISSN (p): 2320-2084, Volume-1, Issue-, July-2013.

[3] J. H. Lee, S. Ohara, T. Nagashima, T. Hasegawa, N. Sugimoto, K.Igarashi, K. Katoh, and K. Kikuchi, "Clock recovery and demultiplexing of high-speed OTDM signal through combined use of bismuth oxide nonlinear fiber and erbium-doped bismuth oxide fiber," IEEE Photonics Technology Letters, vol. 17, no. 12, pp. 2658-2660, Dec. 2005.

[4] O. Ozolin, G. Ivanovs "Realization of optimal FBG BandPass Filters for High Speed DWDM" Journal of Electronics and Electrical Engineering, 2009. No. 4(92) ISSN $1392-1215$.
[5] Vineet Tiwari, Akash Mohan Soni, Abhishek Tripathi and Gireesh G. Soni, "Analysis of $6 \times 10$ Gbps Spectrally Efficient Optical AP-DCDM based Communication System", 2014 International Conference on Computer Communication and Informatics (ICCCI -2014), Jan. 03 05, 2014, Coimbatore, INDIA.

[6] A. Malekmohammadi, M.K. Abdullah, G.A. Mahdiraji, "Analysis Of Return-To-Zero-On-Off-Keying Over Absolute Polar Duty Cycle Division Multiplexing In Dispersive Transmission Medium" IET Optoelectronics, Vol. 3, No. 4, pp. 197-206., 2009.

[7] Amin Malekmohammadi, M.K.Abdullah, A.F.Abas, G.A.Mahdiraji,M.Mokhtar, "Absolute Polar Duty Cycle Division Multiplexing(APDCDM); Technique for Wireless Communications", InternationalConference on Computer and Communication Engineering, KualaLumpur, Malaysia, May 13-15, 2008.

[8] A. Singh, G.G. Soni, A. Tripathi, "Design of $3 \times 60$ Gbps DCDM basedWDM system", International Conference on Optical Engineering, 2012.

[9] M. K. Abdullah, G. A. Mahdiraji, M. F. Elhag, A. F. Abas, E. Zahedi,and M. Mokhtar, "A New Duty Cycle Based Digital Multiplexing Technique”, proceedings of IEEE International Conference on Telecommunications, 14-17 May, 2007. 